\title{
TAX REFORM: IS IT WELFARE-ENHANCING OR WELFARE-REDUCING?
}

\author{
Roshaiza Taha \\ Universiti Malaysia Terengganu \\ Norsiah Ahmad* \\ Universiti Sultan Zainal Abidin \\ Wan Anisah Endut \\ Universiti Sultan Zainal Abidin \\ Saeed Rabea Ali Baatwah \\ Shaqra University
}

\begin{abstract}
The ongoing tax reform in Malaysia has triggered our motivation to understand the effect of such reform on the public since the government has continuously emphasised that the changes would not burden the consumer. Whether this is a myth or reality is deemed interesting to ponder upon. Thus, this study aims to provide evidence concerning Malaysian tax reform on consumer welfare by looking at the price effect, consumer burden, and inflation. Price observations of the pre-, during and post-reformation period were conducted to provide meaningful evidence. Interestingly, the outcome of the observation rules out the public accusation that the tax reform would boost the price of goods and services and further result in a welfarereducing event. Also, a review of the recent statistics on poverty incidence does not show a negative effect of tax policy changes on society's welfare. It is hoped that the discussion provided in this paper will shed light on the impact of tax reformation in Malaysia, albeit a further thorough examination might be required.
\end{abstract}

Keywords: Tax reform, price of goods and services, poverty and household income

Received: 22 April 2019

Accepted: 20 May 2020

\section{INTRODUCTION}

Despite remarkable growth, poverty incidence remains high and the government has made it the main agenda to be resolved to promote equality. In the developed, developing, and underdeveloped context, poverty issues should be overcome as this could undermine the unity and harmony of the country, and, thus, may distort future growth. Poverty also relates to social inequalities where there exist unequal opportunities and rewards for different groups of society the rich and the poor (Annim, Mariwah, \& Sebu, 2012; Bratanova, Loughnan, Klein, Claassen, \&

\footnotetext{
- Corresponding author: Professor in Accounting \& Taxation, School of Business and Management, Universiti Sultan Zainal Abidin, 21300 Kuala Nerus, Terengganu. Tel: +6019 2700383; Email: norsiah@unisza.edu.my
} 
Wood, 2016). In the current economic environment, specifically, in the developing and underdeveloped context, the rich remain rich and the poor maintain the status quo. In the developed country context, high taxes are imposed on citizens, mainly on high income earners, and the benefits are shared with the less fortunate group through welfare payments aimed at alleviating distress and poverty (McGee, Benk, \& Yüzba, 2019).

It cannot be denied that government revenue generation comes from tax sources on top of other sources of income. However, tax has become a taboo topic for discussion, especially tax on income - at both the individual and corporate level - as people become aggrieved with the fact that they have to give away a portion of their income earned. Exacerbating the situation, was the imposition of a consumer tax, known as the Goods and Services Tax (GST) (a form of value added tax or VAT), in 2015 on every single consumption with few exemptions, which was deemed to add to the burden. The introduction of GST to replace the Sales and Services Tax (SST) during that time became a very hot topic and was seen to be one of the reasons for the collapse of the previous government. This was when the general public believed that GST would increase the price of every single product and service despite the promises of most big firms that they would not increase their prices, and, instead, would absorb the cost of GST themselves (Sanusi, Omar, \& Mohd Sanusi, 2015; Goh, Huei, \& Tay, 2017). In addition to this, the public believed that GST was a new tax imposed on every single product and service without realizing that they had been paying the consumption tax under SST before. The difference being that the tax was embedded in the cost, and, hence, consumers usually did not realise the existence of such a tax as it was not compulsory for the businesses to disclose the information, unlike GST which is more transparent.

To deeply understand the concept of the consumption tax, it is worthwhile examining the history of the implementation of VAT. VAT was first introduced by Germany and France in the form of a general consumption tax during World War I with France modernizing its implementation in the 1950s. Among the benefits of VAT are that it overcomes the issue of government income losses since the imposition of VAT means that all levels of transactions are taxed, and it is also considered as an effective way of generating revenue (Keen and Smith, 2006; Olatunji, 2009, Ling, Osman, Muhammad, Yeng, \& Jin, 2016). To date, 160 countries in the world have implemented VAT/GST (Royal Malaysian Customs Department, 2019). Realistically, convincing the public, businesses, and firms to accept the introduction of GST in Malaysia during the implementation year was not an easy task for the previous government, particularly for the Royal Malaysian Customs Department (RMCD). At that time, the public believed that they would suffer with a price hike and increase in inflation post implementation (Asmuni, Yusoff, \& Mohd Ses, 2017). Generally, the imposition of GST covered all citizens regardless of their level of income, as it was dependent on their consumption (Shaari, Ali, \& Ismail, 2015). As most products are subject to GST, both rich people and people under the poverty line needed to endure the cost as the final users. The question that needs to be raised is, how did the implementation of GST reflect the poverty issue since it reflected the spending ability? Did it worsen the situation or was there no direct effect on the people under the poverty line? In 2018, only two years after its implementation, GST was abolished and replaced with a reintroduced Sales and Services Tax (SST). Again, such a transformation will impact consumers as the adjustment process by the businesses to the new system will involve additional cost. 
This paper is motivated to investigate the impact of the indirect tax reformation in Malaysia on consumers, from SST to GST in 2015, and GST to SST in 2018. Is it welfare-enhancing as promoted by the government, or is it welfare-reducing as per public perception? Throughout this paper, the effect of the indirect tax changes on consumers is discussed by first looking at the effects post GST implementation on the purchasing power of the public, and, secondly, at the effects post transformation from GST to SST. We present a brief discussion on consumption tax and consumer burden by discussing other factors that affect the consumer and the final section presents the conclusion.

\section{LITERATURE REVIEW}

Tax reform has always been a tool to increase government revenue to be utilized in the development of the nation and a way to stimulate investment activities. Tax reform generally focuses on direct and indirect tax revenue, however, similar to any new changes introduced by the government, there are always positive and negative aspects thereto. Higgins and Lustig (2016), in observing the impact of a poverty-reducing, progressive tax, and transfer system on the poor people found that at least $25 \%$ of the poor people paid more taxes than what they received in transfers; a situation that was classified as fiscal impoverishment. In the event of fiscal policy changes, businesses would usually take advantage of the situation, which, later, hurts the final consumer. For instance, in reference to partitioned pricing, Greenleaf, Johnson, Morwitz, and Shalev (2016) argued that customers trapped with the initial low price of a product ended up paying a handsome amount of money because the initial price does not include additional taxes, fees, and surcharges. Although always opposed by the public, reforming tax policy is one of the bold moves that need to be made by governments. Buettner and Madzharova (2018), and Ilzetzki (2018) supported the claim by proving that tax reform usually results in positive effects for the governments.

It is worth diverting the discussion to understand the welfare-enhancing and welfare-reducing concept before one can understand the impact of fiscal policy changes on the public. The welfare-enhancing concept is a situation in which the changes announced by the government will benefit households, such as in the event of fiscal devaluation (Hohberger and Kraus, 2016). In depth, a bold formula coupled with structured social programmes expands the tax base and reduces fiscal distortion, and a good allocation of tax liability can be considered as welfareenhancing, which makes the tax system become more progressive and further reduces inequalities (Ghiaie, Auclair, \& Ntsama, 2019), whilst welfare-reducing can be viewed as an inverse situation. For instance, a tax policy reform announced by the government that may harm the household, such as reducing the purchasing power, can be considered to be a welfarereducing scenario (Stähler, 2019). How the government manages the increased prices in consumer goods results from various reasons that evidently contribute to the situation of welfareenhancing and welfare-reducing quite differently. Nandy, Daoud, and Gordon (2016) found that different policies applied by countries in response to food price increases provide different results in mitigating the impacts on the poor. When Ethiopia and Nigeria were affected by increasing food prices during a crisis between 2000 and 2013, Ethiopia appeared to protect poor children better than Nigeria, despite being a much poorer country in terms of GDP per head. 
In theory, the imposition of tax, as discussed by Boadway and Song (2016), should be done by looking at the condition where linear and non-linear income taxation is practised in the country. For example, in reducing the impact of a price increase and promoting a welfare improving condition due to the announcement of tax reform, taxing products that are considered to be necessities at a lower rate than luxury products has a favourable effect on the consumer and vice versa. This theory is in line with the previous discussion by Fairfield (2013), Coxhead, Wattanakuljarus, and Nguyen (2013), and Oberholzer and Stack (2014) concerning the importance of scrutinizing the effect of introducing a new fiscal reform and providing equality in formulating a new policy that specifically affects the poor and elite group. Choi, Hirata, and Kim (2017) emphasized the interchangeable role between direct and indirect tax. For instance, in the case of Japan, losses due to corporate income tax cuts were financed by an increase in lump-sum tax or consumption tax.

Managing the acceptance of tax changes by the public is not an easy task, especially if the changes are not favourable and might distort the spending pattern due to its effect on the price of products. Tax increases by the government will be opposed by the public as this would become an additional burden to them. Although it is hard to accept the change, action should be taken to overcome the burden of such increases. Schandlbauer (2017) highlighted that different approaches will be used by financial institutions to tackle the issue of tax increases. Bettercapitalized banks increase their long-term non-depository debt to gain benefit from a large tax shield and likewise for worse-capitalized banks to avoid losses due to tax rate increases. However, in the situation where the announcement of tax reform is related to reducing the burden of the public, it will always be accepted by the public as this will help them to ease the pain of the high cost of living nowadays. Focusing on the education sector, Elsayed (2016) emphasized the ability of improving the education tax benefits to assist in the completion of studies, especially for those who attend private colleges and institutions that offer a longer period of study completion.

The failure or success of any tax policy reform is again determined by the acceptance of the public as well as the tendency of compliance among them. Studies on tax compliance are extensive and large (Benno, 2002; Feld \& Tyran, 2002; Mittone, 2006; Torgler \& Valev, 2010; Doerrenberg, 2015). Similar to the previous findings in the earlier studies listed, Cyan, Koumpias, and Martinez-Vazquez (2016) explicated a case in Pakistan, where groups with lower labour force participation showed a more positive attitude towards tax compliance, and showed more difficulty in controlling large groups of the labour force in certain industries. In addition, educated persons tend to be more compliant as they feel obliged to follow the law compared to other groups.

As mentioned earlier, tax reform is usually designed related to direct and indirect tax sources. Focusing on the indirect tax revenue source, introducing VAT/GST becomes the most popular consumption tax option among developed, developing, and underdeveloped governments despite its unpopularity with the public. The introduction of VAT/GST seems to combat the noncompliance issues in every nation (Grgić \& Terzić, 2014). This happens when this system reaches every single layer of citizens as it targets consumption. While VAT/GST is considered to be an efficient tool to promote tax compliance, its introduction will affect the spending pattern of consumers. In fact, every single consumer, regardless of whether they are with or without a source of income, will be affected. In discussing this, Carvalho and Lian (2010) highlighted that 
the introduction of GST in Canada in 1991 affected private spending patterns. The sectors that benefit from the introduction of such taxes are services and savings, while lower consumption has been observed on commodity goods.

Adding to the discussion, de Quatrebarbes, Boccanfuso, and Savard (2016) emphasized how the implementation of VAT can become the best tool to battle poverty. This study compares the effect of introducing a flat rate, which is best suited for economic efficiency and a higher statutory VAT rate with the exemption of staple food as a strategy for poverty reduction. This study supports the idea of introducing different VAT rates to cater for different economic sectors, as discussed by Jensen and Wanhill (2002) which focused on the tourism sector. The introduction of VAT is also associated with consumer burden and inflation, as these two indicators reflect the purchasing power of citizens. Thus, as astute governments, the implementation or reformation of the tax structure usually relates to the consumption tax changes or alterations to income tax rates, which witnesses the shift of balance between direct and indirect taxation. Furthermore, there are good economic and administrative reasons for countries to move towards commodity taxation systems, such as VAT or its equivalent, general sales tax (GST), and it is recommended for countries that have already implemented such taxes to revisit the current system to review its effectiveness.

\section{THE IMPLICATION OF TAX REFORM}

It is quite interesting to see the impact of drastic indirect tax reform in Malaysia since 2015 from SST - GST - SST. The decision to introduce GST was made due to unstable economic conditions and the depreciation of the Malaysian ringgit (MYR) by more than 20 percent relative to the US Dollar (USD) up until 1 September 2014. To understand this, it is worth looking into the first phase of such reformation, when the decision to change the tax system from SST to GST was made. As highlighted earlier, 160 countries have implemented consumption tax, showing how popular it is among the governments generally. Table 1 shows 21 countries in Asia that have implemented VAT/GST, with the Republic of Korea being the first country to introduce $\mathrm{VAT} / \mathrm{GST}$ in this region.

Table 1: Current rate of VAT/GST in Asia

\begin{tabular}{cccc}
\hline \hline No & Country & Implementation year & Current Rate (\%) \\
\hline 1 & Korea, Rep. & 1977 & 10 \\
2 & Indonesia & 1984 & 10 \\
3 & Japan & 1989 & 5 \\
4 & Pakistan & 1990 & 16 \\
5 & Bangladesh & 1991 & 15 \\
6 & Thailand & 1992 & 7 \\
7 & Singapore & 1993 & 7 \\
8 & China & 1994 & 17 \\
9 & Nepal & 1997 & 13 \\
10 & Mongolia & 1998 & 10 \\
11 & Philippines & 1998 & 12 \\
12 & Kyrgyz Republic & 1999 & 20 \\
13 & Cambodia & 1999 & 10 \\
\hline
\end{tabular}




\begin{tabular}{cccc}
\hline \hline No & Country & Implementation year & Current Rate (\%) \\
\hline 14 & Vietnam & 1999 & 10 \\
15 & Jordan & 2001 & 16 \\
16 & Sri Lanka & 2002 & 12 \\
17 & Papua New Guinea & 2004 & 10 \\
18 & India & 2005 & 12.5 \\
19 & Iran & 2008 & 5 \\
20 & Laos & 2009 & 10 \\
21 & Malaysia & 2015 & 6 \\
\hline \hline
\end{tabular}

Source: Ministry of Finance, Malaysia (2018)

From these 21 countries, only five countries imposed these taxes below 10\%, with Iran imposing the lowest rate at $5 \%$ followed by Malaysia at $6 \%$ in 2015 . The highest rate was charged by the Kyrgyz Republic at 20\%. The rate of GST when it was first imposed by Singapore was among the lowest at 3\% before their government increased the rate gradually to 4\% (2003), 5\% (2004), and $7 \%$ (2007). Another ASEAN country that increased its rate of GST was the Philippines, from $10 \%$ to $12 \%$, showing the possibility of increasing GST rate in any country. In fact, it is quite unlikely for the rate to be reduced once it is imposed.

In observing the pattern of consumer price index and inflation rate prior to the implementation year, during the year of implementation and post implementation year, as per Table 2, an inconsistent up and down pattern can be seen for the inflation rate. A total of 11 countries showed a reduced rate of inflation that resulted from the introduction of VAT/GST, and the remaining 10 countries showed an increased rate of inflation. However, for CPI, the consistent increasing trend was recorded during the observation period. In fact, such an increasing trend was consistently reported every year implying that tax structure reformation is not the sole factor influencing the consumer burden. Other factors, such as the exchange rate (Parker, 2014), might also contribute to the price increase.

Table 2: CPI and Inflation rate during pre-, current, and post VAT/GST implementation period.

\begin{tabular}{llccccccc}
\hline \hline & & \multirow{2}{*}{ Year of } & \multicolumn{3}{c}{ CPI } & \multicolumn{3}{c}{ INFLATION } \\
\cline { 6 - 9 } No & & VAT/ & \multirow{2}{*}{ Pre } & \multirow{2}{*}{ Current } & Post & Pre & Current & Post \\
\hline 1 & Korea, Rep. & 1977 & 12.64 & 13.93 & 15.94 & 15.30 & 10.17 & 14.46 \\
& & 1984 & 7.63 & 8.43 & 8.83 & 11.79 & 10.46 & 4.73 \\
2 & Indonesia & 1989 & 89.65 & 91.69 & 94.47 & 0.66 & 2.28 & 3.03 \\
3 & Japan & 1990 & 16.37 & 17.85 & 19.95 & 7.84 & 9.05 & 11.79 \\
4 & Pakistan & 1991 & 32.25 & 34.30 & 35.55 & 6.13 & 6.36 & 3.63 \\
5 & Bangladesh & 1992 & 52.60 & 54.78 & 56.59 & 5.71 & 4.14 & 3.31 \\
6 & Thailand & 1993 & 76.01 & 77.75 & 80.16 & 2.26 & 2.29 & 3.10 \\
7 & Singapore & 1994 & 44.50 & 55.30 & 64.58 & 14.58 & 24.24 & 16.90 \\
8 & China & 1997 & 42.34 & 44.04 & 48.99 & 9.22 & 4.01 & 11.24 \\
9 & Nepal & 1998 & 33.01 & 36.09 & 38.83 & 36.56 & 9.36 & 7.56 \\
10 & Mongolia & 1998 & 52.90 & 57.78 & 61.22 & 5.59 & 9.23 & 5.94 \\
11 & Philippines & 1999 & 30.11 & 41.25 & 48.97 & 10.46 & 37.03 & 18.70 \\
12 & Kyrgyz Republic & 1999 & 57.22 & 59.51 & 59.04 & 14.81 & 4.01 & $(0.79)$ \\
13 & Cambodia & 1999 & 47.03 & 48.97 & 48.13 & 7.27 & 4.12 & $(1.71)$ \\
14 & Vietnam & 2001 & 66.12 & 67.29 & 68.53 & 0.67 & 1.77 & 1.83 \\
15 & Jordan & 2002 & 41.65 & 45.62 & 48.50 & 14.16 & 9.55 & 6.31 \\
16 & Sri Lanka & & & & & & &
\end{tabular}




\begin{tabular}{llccccccc}
\hline \hline \multirow{2}{*}{ No } & \multirow{2}{*}{ Country } & Year of & \multicolumn{3}{c}{ CPI } & \multicolumn{3}{c}{ INFLATION } \\
\cline { 6 - 9 } & & VAT/ & Pre & Current & Post & Pre & Current & \multirow{2}{*}{ Post } \\
\hline 17 & Papua New Guinea & 2004 & 74.16 & 75.76 & 77.11 & 14.71 & 2.16 & 1.78 \\
18 & India & 2005 & 63.15 & 65.83 & 69.87 & 3.77 & 4.25 & 6.15 \\
19 & Iran & 2008 & 63.72 & 80.00 & 90.80 & 17.21 & 25.55 & 13.50 \\
20 & Laos & 2009 & 94.32 & 94.36 & 100.00 & 7.63 & 0.04 & 5.98 \\
21 & Malaysia & 2015 & 110.50 & 112.80 & 115.20 & 3.20 & 2.10 & 2.10 \\
\hline \hline
\end{tabular}

Source: World Development Indicators (2018)

\section{RESEARCH DESIGN}

The study adopts the observation and survey method of research in which the collection of data is carried out by observing the identified phenomena. The study follows a structured or systematic observation in which pre-specified data are collected according to a pre-defined schedule (Dudovskiy, 2016). The pre-specified observation data are the price of goods and services before and after the implementation of GST on April 2015. The price was collected on a weekly basis for 11 weeks from 1 March 2015 to 10 May 2015 in one of the cities in the East Coast Region of Peninsular Malaysia. Since, the implementation of GST is assumed to affect the price of products, especially necessity goods that would burden the public during an unstable economy, the study identifies 174 goods and services. These include beverages, bleach, clothing and footwear, computer and accessories, electronic appliances, food, fruits, fuel, grocery, hardware, hotels, watches, medicines, personal hygiene products, pest control, sports, stationery, reading materials, tobacco, and transportation.

The data were analysed based on the increase or decrease in prices before and after the implementation of GST. Some secondary data from the Department of Statistics Malaysia and the Ministry of Finance Malaysia are also employed in the discussion.

\section{RESULTS AND DISCUSSION}

Prior to GST implementation, the government highlighted that the majority of the prices of goods and services would either drop or be maintained with only a few prices increasing due to conditions, such as the exchange rate or because the product might not previously have been subject to tax. However, during the early implementation of GST, a number of stories and news were shared by the public claiming a spike in almost all prices. Many Malaysians expressed their concern about the rise in living costs in the media (Mallow, 2016; Sidhu, 2017).

Based on the prices collected, the study found that, five weeks after the implementation of GST, only $53(30.5 \%)$ of the 174 products observed increased in price, while the prices of six products (3.4\%) reduced and 115 products $(66.1 \%)$ maintained their prices. The lowest and highest increase in price were $1.63 \%$ and $100.20 \%$, respectively. The highest price increase was for electrical appliances. The lowest percentage of price decrease post GST was recorded for vehicles. The highest rate of price decrease was vegetables, which were not in the list of products subjected to GST. The summary of the price observation is reported in Table 3. 
Table 3: Summary of the changes in the price of goods and services

\begin{tabular}{|c|c|}
\hline Explanation & No \\
\hline Number of products observed & 174 \\
\hline Number of products with the price increased post GST & 53 \\
\hline Number of products with the price decreased post GST & 6 \\
\hline Number of products with the price maintained post GST & 115 \\
\hline The lowest price increase post GST & $1.63 \%$ \\
\hline The highest price increase post GST & $100.20 \%$ \\
\hline The lowest price decrease post GST & $0.53 \%$ \\
\hline The highest price decrease post GST & $15.52 \%$ \\
\hline
\end{tabular}

In reviewing the statistics related to household income and poverty incidence published by the Department of Statistics Malaysia in 2016, even with GST, both statistics showed improvements in that poverty incidence decreased from $0.6 \%$ to $0.4 \%$, and the monthly income mean by household group, including B40, M40, and T20, increased from $5.8 \%$ to $6.9 \%$ in 2016 , which ruled out the negative effect of GST. Table 4 displays the poverty incidence and national household income for Malaysia in 2014 and 2016.

Table 4: Poverty incidence and national household income for Malaysia in 2014 and 2016

\begin{tabular}{lcc}
\hline \hline & $\mathbf{2 0 1 4}$ & $\mathbf{2 0 1 6}$ \\
\hline Incidence of poverty & 0.6 & 0.4 \\
Monthly household income & RM6,141 & RM6,958 \\
Monthly household income T20 & RM14,305 & RM16,088 \\
Monthly household income M40 & RM5,662 & RM6,502 \\
Monthly household income B40 & RM2,537 & RM2,848 \\
\hline \hline
\end{tabular}

Source: Department of Statistics Malaysia $(2015,2017)$

Adding to this, the household income by state also showed a positive increase. Based on these statistics, it can be said that GST does not really affect the quality of life of Malaysian citizens. However, although one can argue that such results may be obtained due to the high gap between the extremely poor and the extremely rich, as reported in Table 4, this is a fact that should be further investigated. The impact of the increasing cost of living may not be significant to Malaysians in the high-income group, but the rise in consumer burden is definitely felt by the low-income group. In addition, although the poverty rate can be reduced, it is quite difficult for it to be totally eliminated as the definition of poverty itself varies from time to time.

In brief, it is difficult to generalize the reason for the price increase, and whether it is due to GST implementation or other factors. The period of GST implementation by the Malaysian government combined with the diminishing value of the ringgit, sluggishness in commodity prices, and plunging crude oil prices seems to have had a great influence on the price variation of goods and services (Malaysian Institute of Economic Research, 2016). The implementation of GST is believed to negatively influence the purchasing power due to the high price charged for each product and service (Ling et al., 2016).

The second phase of tax reformation in Malaysia was in 2018. Two years after its introduction, GST was abolished and replaced with a slightly newer version of SST. The abolishment of GST resulted in mixed feedback from the public. The pro-GST camp claimed that GST was a victim of populist politics since to realise its implementation took years of political persuasion. In 
contrast, the pro-SST camp defended how GST had burdened the consumers, as the tax was imposed on every layer of consumption, unlike the SST, which was a single stage tax. Although the positive or negative impact on the public is not yet proven, as no statistics concerning the incidence of poverty and monthly household income were available, it is worth examining the impact on the government. The transition from GST back to the new SST resulted in a significant drop in government revenue. Economists believe that, in the short term, this would jeopardise development projects that would have been funded by the higher revenue collected through GST. Table 5 presents the pattern of tax revenue collection based on the extracted information of revenue collection by the government from 2014 to 2018. GST was a life-saver during the significant drop in revenue collection due to the instability of the crude oil market in 2015 . The losses in the government revenue due to the implementation of SST in 2018 to replace GST resulted in a decline of indirect tax revenue collection. However, the increase in crude oil price in 2018 reduced the impact of the losses.

Table 5: Direct tax and Indirect tax collection 2014-2018

\begin{tabular}{|c|c|c|c|c|c|}
\hline Type of tax & 2014 & 2015 & 2016 & 2017 & 2018 \\
\hline Direct tax & 126,742 & 117,770 & 109,608 & 116,024 & 133,474 \\
\hline Petroleum & 26,956 & 11,559 & 8,422 & 11,761 & 16,845 \\
\hline Indirect tax & 37,462 & 53,670 & 59,735 & 61,634 & 41,226 \\
\hline Sales Tax & 10,939 & 5,223 & 103 & 47 & 2,880 \\
\hline Service Tax & 6,278 & 3,038 & 103 & 15 & 1,120 \\
\hline Goods and Services Tax & & 27,012 & 41,206 & 44,290 & 19,100 \\
\hline
\end{tabular}

Source: Ministry of Finance, Malaysia (2018)

\section{CONCLUSION}

The present paper was conducted to observe the impact of consumption tax reformation, better known as SST and GST reformation, on Malaysian citizens. Looking at the impact of the policy changes from SST to GST in 2015, based on our observation of the price of goods and services in the post implementation period, there were indeed price changes on certain goods and services. However, GST was not the sole factor that influenced such changes, as, during that time, Malaysia was also facing instability in the crude oil price together with the diminishing value of the ringgit since 2014. It can be considered to be a lifesaver to the Malaysian government to make up for the loss of revenue due to the major drop in the crude oil price in 2015. A further review of the poverty incidence and household income did not portray a negative effect of GST implementation on the society. Indeed, the poverty incidence improved when compared between 2014, which was pre-GST, and 2016, which was post-GST implementation.

Focusing on the abolishment of GST in 2018, the impact on the public is not yet proven as no statistical data are available. The impact on the government is clear in that the collection of revenue from indirect tax sources were proven to be declining. Moreover, this study allows the public to understand the impact of tax reformation albeit further examination may provide more fruitful findings. It would be more meaningful if the opinions of the public and the policymakers were viewed to determine the reality of such policy reform. This might be an avenue for future research. Ultimately, although taxes, regardless of direct or indirect, imposed on the payers are 
seen as a burden, one should realize that it is necessary to fund the development for the greater good of the public. To gain public confidence, it is suggested that thorough reporting be disclosed concerning how the revenue collected is being channelled. Finally, to decide whether tax reform is welfare-enhancing or welfare-reducing is not an easy task. If we were to ask the government, the answer would definitely be the former, while the public would say the latter. The most important thing is, one should understand that tax is not the sole factor that determines the consumer burden.

This study may have its own limitations. For one, the study only focused on the East Coast regions of Peninsular Malaysia. Thus, generalising the findings to other areas, especially the East Malaysia (Sabah and Sarawak) should be done with caution, as it is generally acknowledged that the prices of goods and services in those areas are higher than in Peninsular Malaysia due to the transportation costs. However, since this study is based on the changes in prices and not the actual prices of goods, some findings might be relatable albeit not conclusive. Future studies should include samples from a greater geographic area or be expanded to include East Malaysia; Sabah, and Sarawak.

\section{ACKNOWLEDGEMENT}

We gratefully acknowledge Universiti Sultan Zainal Abidin, Malaysia, for its financial help for the research under grant UniSZA /1/2015/SRGS/6.

\section{REFERENCES}

Annim, S. K., Mariwah, S., \& Sebu, J. (2012). Spatial inequality and household poverty in Ghana. Economic Systems, 36(4), 487-505.

Asmuni, S., Yusoff, S., \& Mohd Ses, N. S. (2017). Acceptance towards Goods and Services Tax (GST) among local business communities. Journal of Emerging Economies \& Islamic Research, 5(4), 62-72.

Benno, T. (2002). Speaking to theorists and searching for facts: tax morale and tax compliance in experiments. Journal of Economics Surveys, 16(5), 657-684.

Boadway, R. \& Song, Z. (2016). Indirect taxes for redistribution: should necessity goods be favored? Research in Economics, 70(1), 64-88.

Bratanova, B., Loughnan, S., Klein, O., Claassen, A., \& Wood, R. (2016). Poverty, inequality, and increased consumption of high calorie food: experimental evidence for a causal link. Appetite, 100, 162-171.

Buettner, T., \& Madzharova, B. (2018). WTO membership and the shift to consumption taxes. World Development, 108, 197-218.

Carvalho, E., \& Lian, Z. (2010). The impact of goods and services tax on the pattern of Canadian consumer spending and saving. The Journal of Economic Asymmetries, 7(1), 123-136.

Choi, Y., Hirata, H., \& Kim, S. H. (2017). Tax reform in Japan: is it welfare-enhancing? Japan and the World Economy, 42, 12-22.

Coxhead, I., Wattanakuljarus, A., \& Nguyen, C. V. (2013). Are carbon taxes good for the poor? A general equilibrium analysis for Vietnam. World Development, 51, 119-131. 
Cyan, M. R., Koumpias, A. M., \& Martinez-Vazquez, J. (2016). The determinants of tax morale in Pakistan. Journal of Asian Economics, 47, 23-34.

Department of Statistics Malaysia. (2015). Report of Household Income and Basic Amenities Survey 2014. Retrieved December 15, 2018, from https:/www.dosm.gov.my.

Department of Statistics Malaysia. (2017). Report of Household Income and Basic Amenities Survey 2016. Retrieved December 15, 2018, from https://www.dosm.gov.my.

Doerrenberg, P. (2015). Does the use of tax revenue matter for tax compliance behavior? Economics Letters, 128, 30-34.

Dudovskiy, J. (2016). The Ultimate Guide to Writing a Dissertation in Business Studies: A Stepby-Step Assistance. Retrieved December 15, 2018, from https://researchmethodology.net/research-methods/qualitative-research/observation/.

Elsayed, M. A. A. (2016). The impact of education tax benefits on college completion. Economics of Education Review, 53, 16-30.

Fairfield, T. (2013). Going where the money is: strategies for taxing economic elites in unequal democracies. World Development, 47, 42-57.

Feld, L. P., \& Tyran, J. R. (2002). Tax evasion and voting: an experimental analysis. Kyklos, 55(2), 197-221.

Ghiaie, H., Auclair, G., \& Ntsama, J. F. N. N. (2019). Macroeconomic and welfare effects of tax reforms in emerging economies: a case study of Morocco. Journal of Policy Modelling, 41(4), 666-699.

Goh, P. J., Huei, C. T., \& Tay, A. G. M. (2017). Consumers' perception towards the implementation of Goods and Services Tax (GST) in Malaysia: a review paper. Journal of Global Business and Social Entrepreneurship, 1(4), 17-23.

Greenleaf, E. A., Johnson, E. J., Morwitz, V. G., \& Shalev, E. (2016). The price does not include additional taxes, fees, and surcharges: a review of research on partitioned pricing. Journal of Consumer Psychology, 26(1), 105-124.

Grgić, R., \& Terzić, S. (2014). Tax evasion in Bosnia and Hercegovina and business environment, Procedia - Social and Behavioral Sciences, 119, 957-966.

Higgins, S., \& Lustig, N. (2016). Can a poverty-reducing and progressive tax and transfer system hurt the poor? Journal of Development Economics, 122, 63-75.

Hohberger, S., \& Kraus, L. (2016). Is fiscal devaluation welfare enhancing? Economic Modelling, $58,512-522$.

Ilzetzki, E. (2018). Tax reform and the political economy of the tax base. Journal of Public Economics, 164, 197-210.

Jensen, T. C., \& Wanhill, S. (2002). Tourism's taxing times: value added tax in Europe and Denmark. Tourism Management, 23(1), 67-79.

Keen, M., \& Smith, S. (2006). VAT fraud and evasion: what do we know and what can be done? National Tax Journal, 59(4), 861-887.

Ling, S. C., Osman, A., Muhammad, S., Yeng, S. K., \& Jin, L. Y. (2016). Goods and Services Tax (GST) compliance among Malaysian consumers: the influence of price, government subsidies and income inequality. Procedia Economics and Finance, 35, 198-205.

McGee, R. W., Benk, S., \& Yüzba, B. (2019). Should governments tax the rich and subsidize the poor? A comparative study of Muslim and Christian respondents. Religions, 10(72), 1-10.

Malaysian Institute of Economic Research. (2016). Malaysian Economic Outlook. Retrieved December 15, 2018, from https://www.mier.org.my/old/outlook/archives /2016_01.html. 
Mallow, M. S. (2016 September 21). Budget must reduce burden of rising costs. Retrieved December 15, 2018 from https:/www.thestar.com.my/opinion/letters /2016/09/21/budget-must-reduce-burden-of-rising-costs/\#rhM9mkYimWb71SYE.99.

Mittone, L. (2006). Dynamic behaviour in tax evasion: an experimental approach. The Journal of Socio Economics, 35(5), 813-835.

Nandy, S., Daoud, A., \& Gordon, D. (2016). Examining the changing profile of undernutrition in the context of food price rises and greater inequality. Social Science \& Medicine, 149, 153-163.

Oberholzer, R., \& Stack, E. (2014). Perceptions of taxation: a comparative study of different population groups in South Africa. Public Relations Review, 40, 226-239.

Olatunji, O. C. (2009). A review of value added tax (VAT) administration in Nigeria. International Business Management, 3(4), 61-68.

Parker, M. (2014). Exchange rate movements and consumer prices: some perspectives. Reserve Bank of New Zealand: Bulletin, 77(1), 31-42.

Royal Malaysian Customs Department (2019). Countries implementing GST or VAT. Retrieved March 15, 2019 from http://www.customs.gov.my/en/cp/Pages/cp_ci.aspx.

Sanusi, S., Omar, N., \& Mohd Sanusi, Z. (2015). Goods and Services Tax (GST) governance in the Malaysian new tax environment. Procedia Economics and Finance, 31, 373-379.

Schandlbauer, A. (2017). How do financial institutions react to a tax increase? Journal of Financial Intermediation, 30, 86-106.

Shaari N., Ali, A., \& Ismail, N. (2015). Student's awareness and knowledge on the implementation of Goods and Services Tax (GST) in Malaysia. Procedia Economics and Finance, 31, 269-279.

Sidhu, J. S. (2017). Analysts say food inflation still a big problem for many households. Retrieved December 15, 2018 from https://www.thestar.com.my/business/business news/2017/12/16/analysts-say-food-inflation-still-a-big-problem-for-many-households/\#6 PILQZF2KWCd0mFi.99.

Stähler, N. (2019). Who benefits from using property taxes to finance a labor tax wedge reduction? Journal of Housing Economics, 46, 1-15.

Torgler, B., \& Valev, N. T. (2010). Gender and public attitudes toward corruption and tax evasion. Contemporary Economic Policy, 28(4), 554-568.

World Development Indicators. (2018). DataBank. Retrieved March 15, 2019, from https:/databank.worldbank.org/source/world-development-indicators. 